\title{
Study of Thyroid Function in Adolescent Girls with Intellectual Disabilities
}

\author{
Joshi GA ${ }^{1}$, Joshi PG \\ ${ }^{1}$ Dr Ganesh Arun Joshi, Composite Regional Centre for persons with disabilities (CRC), Bhopal, Punarwas Bhavan, Khajuri \\ Kalan, Piplani, Bhopal, Madhya Pradesh, India, ${ }^{2}$ Dr Prajakta Ganesh Joshi, Department of Obstetrics and Gynecology, \\ Chirayu Medical College and Hospital, Bairagarh, Bhopal, Madhya Pradesh, India.
}

Address of Corresponding Author: Dr. Ganesh Arun Joshi, Email: gajjag@gmail.com

\begin{abstract}
Introduction: Thyroxine is an important hormone that ensures proper growth and development throughout life. It has an important role in the development of the reproductive system. Methods: The objective of this study was to evaluate the thyroid status of adolescent girls with disabilities. A survey was undertaken at a residential institution on all adolescent girls with disabilities in 10-19 years age group. There were 21 girls with intellectual disabilities. Their sexual development was noted. Thyroid profile was advised in all subjects. Results: There were 2 girls who had not developed any secondary sexual characters but they showed normal thyroid profile. The thyroid profile was deranged in 1 girl who had Down's syndrome and another girl had subclinical hypothyroidism. Conclusion: The study concludes that thyroid profile should be done at regular intervals in adolescent girls with intellectual disabilities, especially Down's syndrome.
\end{abstract}

Key words: Intellectual Disability, Female Adolescent, Hypothyroidism

\section{Introduction}

Thyroid hormone plays an important role in development and growth. During the process of development, apoptosis and cellular proliferation are balanced by a multihormonal mechanism, the major actor of which is triiodothyronine [1]. Adolescence is described as the period in life when an individual is no longer a child but not yet an adult. It spans the age group of 10-19 years [2]. Many physical, psychological and emotional changes occur during adolescence under the influence of hormones. Recognition of the role of thyroxine in growth and development prompted the implementation of National Programme for Prevention and Control of Iodine Deficiency Disorders [3]. The range of disorders due to thyroxine deficiency is quite vast, including neck swelling, menstrual disorders, recurrent abortions, foetal mal-development, deafness, intellectual deficiency disorder, cerebral palsy etc. [4]. The prevalence of hypothyroidism is 1 in 2640 in newborns in India, higher than the international prevalence [5]. Many countries have introduced routine neonatal screening for thyroid disorders to prevent developmental disabilities by early identification and

Manuscript received: $16^{\text {st }}$ Sep 2014

Reviewed: $29^{\text {th }}$ Sep 2014

Author Corrected: $16^{\text {th }}$ Oct 2014

Accepted for Publication: $22^{\text {nd }}$ Oct 2014

International Journal of Medical Research and Review intervention. Overt hypothyroidism was found in $1.5 \%$ and overt thyrotoxicosis was found in $5.2 \%$ females [6]. Chronic autoimmune thyroiditis is the most common cause of thyroid disorder among children and adolescents and has a wide spectrum of clinical manifestations and a variable clinical course [7]. Juvenile autoimmune thyroiditis was found in 19 of the children (prevalence $0.35 \%$ ), with a female: male sex ratio of $8: 1$. Graves' disease was diagnosed in four children, three girls and one boy (combined 0.07\%) [8]. Congenital hypothyroidism is found in 1 in 3800 worldwide average [9]. Thyroid hormone supports the adolescent growth spurt and physiological goitre may occur. We could not find scientific literature regarding thyroid dysfunction and sexual development in girls with intellectual disabilities.

\section{Material and Methods}

The aim of this study was to describe the thyroid profile in adolescent girls with disabilities and find delay if any in their sexual development. A research question was raised whether thyroid function is normal or deranged in adolescent girls with disabilities and whether it is associated with any delay in sexual development. The study was undertaken on all adolescent girls with 
intellectual disabilities in the age group of 10-19 years in a residential organization caring for children with disabilities. The study was carried out with due permission and along the ethical guidelines of Declaration of Helsinki. We took history from caretakers of the subjects, studied their medical records and carried out their clinical examination. The clinical diagnosis was established. The subjects were examined for secondary sexual characters viz. thelarche and pubic and axillary hair [10]. The thyroid profile viz. T3, T4 and TSH levels in serum, of all subjects were obtained. The findings were analysed in the light of development of reproductive system.

\section{Results}

The study included 21 girls with intellectual deficiency disorder according to the inclusion criteria.

\section{Table 1: Type of subjects}

\begin{tabular}{|l|l|}
\hline Type & No \\
\hline Intellectual deficiency disorder & 16 \\
\hline Intellectual deficiency with cerebral palsy & 5 \\
\hline Total & 21 \\
\hline
\end{tabular}

Sixteen subjects had only intellectual deficiency disorder while five subjects had cerebral palsy in addition (Table 1).

Table 2: Age groups depicting sexual development

\begin{tabular}{|l|l|l|l|l|}
\hline Age & No & Menarche & $\begin{array}{l}\text { Secondary sexual characters not } \\
\text { developed }\end{array}$ & Thyroid profile \\
\hline $10-14$ & 11 & 0 & 6 & Normal \\
\hline $14-16$ & 4 & 2 & 0 & Normal \\
\hline $16-19$ & 6 & 6 & 0 & $\begin{array}{l}\text { Normal }=4 \\
\text { Hypothyroidism }=1 \\
\text { Subclinical hypothyroidism }=1\end{array}$ \\
\hline
\end{tabular}

The number of subjects in different age groups is shown in Table 2. While most of the subjects were found euthyroid, one in the age group of 16-19 years was having hypothyroidism and another in the same age group had subclinical hypothyroidism. Six (29\%) euthyroid subjects did not have any secondary sexual characters viz. axillary hair, pubic hair, thelarche.

Table 3: Level of Intellectual Deficit

\begin{tabular}{|l|l|l|l|}
\hline $\begin{array}{l}\text { Level of } \\
\text { intellectual deficit (IQ) }\end{array}$ & No & $\begin{array}{l}\text { Secondary sexual characters not } \\
\text { developed }\end{array}$ & Thyroid profile \\
\hline Mild $(50-75)$ & 8 & 2 & Normal $=8$ \\
\hline Moderate $(35-49)$ & 7 & 2 & $\begin{array}{l}\text { Normal }=6 \\
\text { Subclinical hypothyroidism }=1\end{array}$ \\
\hline Severe $(20-34)$ & 5 & 1 & $\begin{array}{l}\text { Normal }=4 \\
\text { Hypothyroidism }=1\end{array}$ \\
\hline Profound $(<20)$ & 1 & 1 & Normal $=1$ \\
\hline
\end{tabular}

The intellectual deficiency in these subjects ranged from mild to profound on standard IQ scores (Table 3). Out of these, the one with subclinical hypothyroidism was in moderate range and another with hypothyroidism was in severe range of intellectual deficiency. Six (29\%) subjects across the whole range did not have any secondary sexual characters viz. axillary hair, pubic hair, thelarche.

The TSH values (normal range $=0.30 \mathrm{IU}$ to $5.50 \mathrm{IU}$ ) ranged from $0.79 \mathrm{IU}$ to $8.80 \mathrm{IU}$ with 2 out of the 21 subjects had above normal TSH values (Graph 1). One subject had Down's syndrome and had high TSH (4.76\%). She was the only one in the study who was taking thyroxine over last 3 years. Another subject (4.76\%) had borderline raised TSH. The T3 and T4 values were within normal range in all subjects. Only 8 (38\%) subjects had attained menarche, out of which one 19 years old subject, with Down's syndrome had higher than normal levels of TSH. She had attained menarche at 14 years age and did not have any menstrual complaints. 
Graph 1 - TSH values (ordinate) of 21 subjects (abscissa)

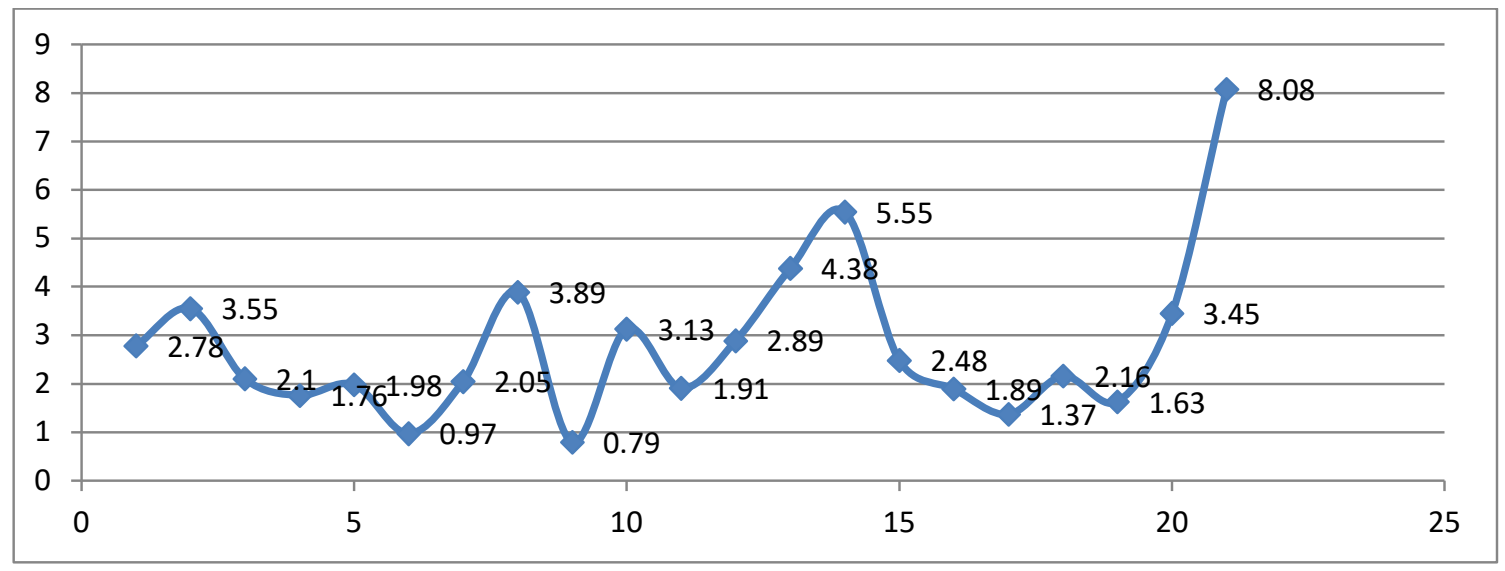

\section{Discussion}

This study was undertaken to find presence of thyroid abnormalities in adolescent intellectually disabled girls and if there is associated delay in sexual maturation. Our study found deranged thyroid profile in two subjects (9.52\%) - one showing overt hypothyroidism and one showing subclinical hypothyroidism.

This frequency is quite higher than $0.113 \%$ prevalence of hypothyroidism in children in age group 11-18 years [11]. Although a study with larger sample size is required for better interpretation of this prevalence.

Deligeoroglou et al stated that thyroid dysfunction is an important cause of primary amenorrhea [12]. In our study, 2 subjects above 16 years age had deranged thyroid profile but they had attained menarche. All subjects younger than 14 years had not attained menarche but had normal thyroid profile. Cebeci et al found thyroid dysgenesis in patients with Down's syndrome [13].

In our study, a 19 year old subject of Down's syndrome, who is on thyroxine supplements since 3 years, had raised TSH. However she had attained menarche by 14 years age and had no menstrual problems. Argente has emphasized thyroid assessment in cases of delayed puberty [14]. In our study, six subjects (29\%) did not have any secondary sexual characters.

Thyroid profile of all subjects was normal. One of these had severe intellectual deficit and the other had cerebral palsy with profound intellectual deficit. Gawlik et al

found that there is high incidence of thyroid autoimmunity in girls with Turner's syndrome after 8 years of age [15]. We did not have any case suspected of Turner's syndrome.
Ozgen et al reported a case with hypothyroidism and precocious puberty [16]. Our study did not come up with any case of precocious puberty. Subclinical hypothyroidism in children is a remitting process with a low risk of evolution toward overt hypothyroidism. Monzani et al found that most of the subjects reverted to euthyroidism or remained subclinically hypothyroid, with a rate of evolution toward overt hypothyroidism ranging between 0 and $28.8 \%$ [17]. Our study came up with one subject of subclinical hypothyroidism.

\section{Limitations}

The number of subjects in the study was too small to apply any statistical analysis to our observations. This may be a reason that the findings of this study do not go in line with studies reported in other conditions.

\section{Conclusion}

The study pointed out that, girls with intellectual disabilities may have delayed puberty irrespective of thyroid function. Down syndrome has deranged thyroid profile indicative of hypothyroidism.

It is recommended that thyroid profile should be done in adolescent girls with intellectual disabilities, especially Down's syndrome, as thyroxine plays an important role in the development of female reproductive system.

A study in the community with a larger number of subjects will be required to associate hypothyroidism and delayed development of the reproductive system. It is recommended that thyroid profile should be repeated at regular intervals in the intellectually disabled. 
Funding: Nil

Conflict of interest: Nil

Permission from IRB: Yes

\section{References}

1. Omer Tarim. Thyroid Hormones and Growth in Health and Disease. J Clin Res Pediatr Endocrinol. Jun 2011; 3(2): 51-55

2. Neena Raina, Patanjali Dev Nayar, Rajesh Mehta, Natasha Dawa. Adolescent Health and Development. In Essential Pediatrics by O P Ghai, V K Paul, Arvind Bagga. $7^{\text {th }}$ Edition. 2009. CBS Publishers. New Delhi, India: 42

3. Chandrakant S. Pandav, Kapil Yadav, Rahul Srivastava, Rijuta Pandav, and M.G. Karmarkar. Iodine deficiency disorders (IDD) control in India. Indian J Med Res. Sep 2013; 138(3): 418-433.

4. Umesh Kapil. National Iodine Deficiency Disorders Control Programme (NIDDCP) in India: Current status and future strategies. Thyroid Research and Practice. 2007;4(2):37-49

5. Desai MP. Disorders of thyroid gland in India. Indian J Pediatr. 1997 Jan-Feb;64(1):11-20.

6. Legakis I, Manousaki M, Detsi S, Nikita D. Thyroid function and prevalence of anti-thyroperoxidase (TPO) and anti-thyroglobulin ( $\mathrm{Tg}$ ) antibodies in outpatients hospital setting in an area with sufficient iodine intake: influences of age and sex.ActaMe Iran.2013;51(1):25-34

7. Skarpa V, Kousta E, Tertipi A, Anyfandakis K, Vakaki M, Dolianiti M, Fotinou A, Papathanasiou A. Epidemiological characteristics of children with autoimmune thyroid disease. Hormones (Athens). 2011 Jul-Sep;10(3):207-14.

8. Jaksić J, Dumić M, Filipović B, Ille J, Cvijetić M, Gjurić G. Thyroid diseases in a school population with thyromegaly. Arch Dis Child. 1994 Feb;70(2):103-6
9. A G Unnikrishnan and U V Menon. Thyroid disorders in India: An epidemiological perspective. Indian J Endocrinol Metab. Jul 2011; 15(Suppl 2):S78-S81

10. Marshall WA, Tannerr JM. Variations in patterns of pubertal changes in girls. Arch Dis Child 1969;44:291303 doi:10.1136/adc.44.235.291

11. Hunter I, Greene SA, MacDonald TM, Morris AD. Prevalence and aetiology of hypothyroidism in the young. Arch Dis Child. 2000 Sep;83(3):207-10

12. Deligeoroglou E, Athanasopoulos N, Tsimaris P, Dimopoulos KD, Vrachnis N, Creatsas G. Evaluation and management of adolescent amenorrhea. Ann N Y Acad Sci. 2010 Sep;1205:23-32. doi: 10.1111/j.17496632. 2010.05669.x.

13. Cebeci AN, Güven A, Yildız M. Profile of hypothyroidism in Down's syndrome. J Clin Res Pediatr Endocrinol. 2013;5(2):116-20.

14. Argente J. Diagnosis of late puberty. Horm Res. 1999; 51 Suppl 3:95-100.

15. Gawlik A, Gawlik T, Januszek-Trzciakowska A, Patel H, Malecka-Tendera E. Incidence and dynamics of thyroid dysfunction and thyroid autoimmunity in girls with Turner's syndrome: a long-term follow-up study. Horm Res Paediatr. 2011;76(5):314-20. doi: 10.1159/ 000331050. Epub 2011 Oct 13.

16. Ozgen T, Güven A, Aydin M. Precocious puberty in a girl with Down syndrome due to primary hypothyroidism.Turk J Pediatr.2009Jul-Aug;51(4):381-3

17. Monzani A, Prodam F, Rapa A, Moia S, Agarla V, Bellone S, Bona G. Endocrine disorders in childhood and adolescence. Natural history of subclinical hypothyroidism in children and adolescents and potential effects of replacement therapy: a review. Eur J Endocrinol. 2012 Dec 10;168(1):R1-R11. doi: 10.1530/EJE-12-0656. Print 2013 Jan

\section{How to cite this article?}

Joshi GA, Joshi PG. Study of Thyroid Function in Adolescent Girls with Intellectual Disabilities. Int J Med Res Rev 2014;2(6):534- 537. doi:10.17511/ijmrr.2014.i06.03 